\title{
FEM Analysis of Punching-Process in Consideration of Micro Die Wear
}

\author{
Takashi Ueda $^{1, a}$, Takashi lizuka ${ }^{1}$ and Shinichi Enoki ${ }^{2}$ \\ 1 Department of Mechanical and System Engineering, Kyoto Institute of Technology, Matsugasaki Goshokaido-cho, Sakyo-ku, 606- \\ 8585 Kyoto, Japan \\ ${ }^{2}$ National Institute of Technology, Nara college, Yata-cho, Yamatokooriyama-shi, 639-1080 Nara, Japan
}

\begin{abstract}
Detailed punching-process analysis is difficult because the punch diameter, sheet thickness, clearance, and die wear of the punching-process are approximately $10 \mu \mathrm{mm}, 1 \mathrm{~mm}, 100 \mu \mathrm{m}$, and $10 \mu \mathrm{m}$, respectively. Furthermore, such analyses have rarely considered die wear. Therefore, in the present study, we set the mesh size in the neighborhood of the die corner radius and the punch to $1 / 10 \mu \mathrm{m}$. Moreover, we analyze the punching process considering die wear. We investigated the stress, incremental strain, and equivalent strain for different levels of die wear.
\end{abstract}

\section{Introduction}

Burr formation in the punching process has adverse effects on post-processing, product accuracy, and worker safety. Thus, a burr-free punching method is desired. Therefore, burr-free blanking using servo press machine on a few steps punching method was reported[1, 2]. However, preventing burr formation during the one step punching process is difficult due to the nature of the formation mechanism of the punching process. Reducing burrs by a simpler method may be possible if the mechanism of burr formation can be clarified. A number of experimental and analytical investigations dealing with burr shape formation have been conducted [3]. The results of these studies revealed that the clearance [4] and die wear [5] primarily affected burr shape formation. However, the formation mechanism of burr shape in the punching process has not yet been clarified. Therefore, Iizuka $[6,7]$ and Sakamoto [8] focused on die wear that affects the formation of burrs and investigated the burr formation mechanism in the punching process. The burr formation mechanism in the punching process has been investigated experimentally while focusing on die wear. However, in order to support the experimental results, a detailed numerical analysis of the burr formation mechanism in the punching process is needed.

Finite element method (FEM) analysis has been reported as being effective in plastic formation. A number of FEM analyses have been conducted in order to clarify the formation mechanism $[9,10]$ and crack growth $[11,12]$ of the punching process. However, detailed analysis of the punching process is more difficult than the analysis of other formation mechanisms. Since orders of magnitude on the punch diameter, the sheet thickness, the clearance, and the die wear of the punching-process are approximately $10 \mathrm{~mm}, 1 \mu \mathrm{mm}, 100 \mu \mathrm{m}$, and $10 \mu \mathrm{m}$, respectively, they are very difference order of magnitude. So, there are reports that the mesh size in the neighborhood of the die corner radius and punch was set $10 \mu \mathrm{m}$ [4, 10]. But, Conventional analyses of the punching process rarely consider micro die wear. Therefore, we set the mesh size in the neighborhood of the die corner radius and punch to $1 / 10 \mu \mathrm{m}$. Moreover, we analyze the punching process while considering die wear. We varied the die wear amount as $10 \mu \mathrm{m}, 20 \mu \mathrm{m}$, $30 \mu \mathrm{m}$, and $40 \mu \mathrm{m}$. We investigated the hydrostatic pressure distribution, the equivalent plastic strain distribution, and the plastic incremental strain distribution for different levels of die wear in the neighborhood of the die corner radius.

\section{Analysis method}

The punching process analysis of the present study was conducted using Simufact.forming12.0.3 (Simufact Engineering System). In the present study, an axisymmetric two-dimensional model was used as an analysis model, as shown in Figure 1. At this time, $R_{\mathrm{d}}, R_{\mathrm{p}}$ and $R_{\mathrm{h}}$ are die corner radius, punch corner radius and die holder shoulder round. We simulated the case in which a blank was punched by a metal punch with a diameter of 4 $\mathrm{mm}$. Cold-rolled steel sheet (SPCC) with a thickness of $1.6 \mathrm{~mm}$ was used as blank. The punch and die holder are rigid bodies. The coefficient of friction between the punch and die and the blank was 0.2. The blank was subjected to a forced displacement of $1.4 \mathrm{~mm}$ with a processing velocity of $500 \mathrm{~mm} / \mathrm{s}$. The base mesh size of the blank in this analysis was set to $37.5 \mu \mathrm{m}$. The mesh size in the neighborhood of the die corner radius and the

a Corresponding author: m5623104@edu.kit.ac.jp 
punch was set to $4.7 \mu \mathrm{m}$. The clearance was $4.69 \%$. In the analysis, the die corner radius $R_{\mathrm{d}}$ was varied as 10 $\mu \mathrm{m}, 20 \mu \mathrm{m}, 30 \mu \mathrm{m}$, and $40 \mu \mathrm{m}$, and the punch corner radius $R_{\mathrm{p}}$ and die holder shoulder round $R_{\mathrm{h}}$ were set to 20 $\mu \mathrm{m}$.

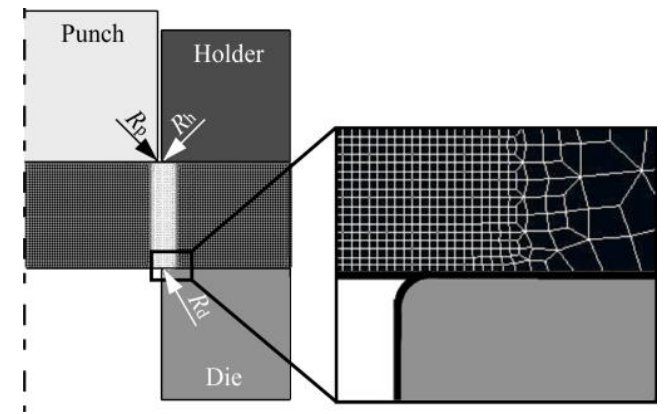

Figure 1. Analysis model.

\section{Analysis result}

\subsection{Plastic incremental strain}

For a stroke of $1 \mathrm{~mm}$, the plastic incremental strain distribution is shown in Figure 2 for die corner radius radii of $10 \mu \mathrm{m}, 20 \mu \mathrm{m}, 30 \mu \mathrm{m}$, and $40 \mu \mathrm{m}$.

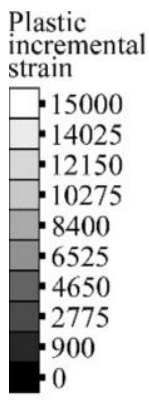

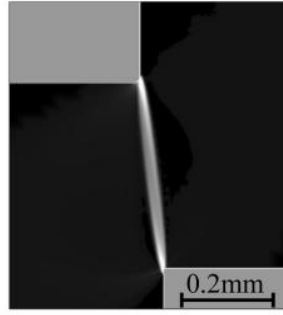

(a) $\mathrm{Rd}=10 \mu \mathrm{m}$

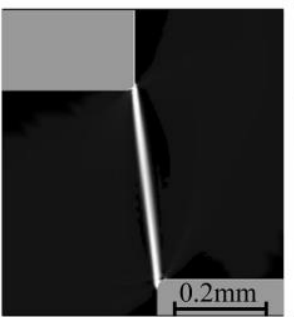

(c) $\mathrm{Rd}=30 \mu \mathrm{m}$

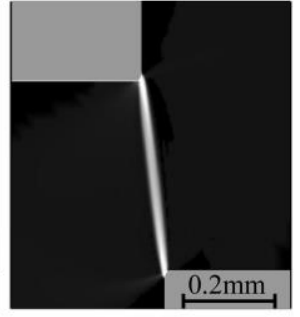

(b) $\mathrm{Rd}=20 \mu \mathrm{m}$

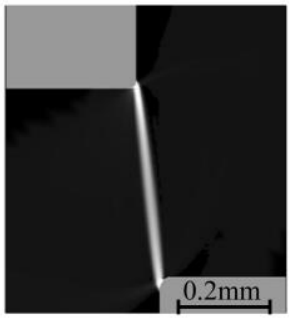

(d) $\mathrm{Rd}=40 \mu \mathrm{m}$
Figure 2. Plastic incremental strain distribution with a stroke of $1 \mathrm{~mm}$.

As shown in Figure 2, thin layer shear is thought to occur in the domain linking the punch corner radius and the die corner radius because high plastic incremental strain is confirmed in this region. Next, we confirm plastic incremental strain in the neighborhood of the die corner radius for stroke of $1 \mathrm{~mm}, 1.2 \mathrm{~mm}$, or $1.28 \mathrm{~mm}$. The plastic incremental strain distributions are shown for die corner radius radii of $20 \mu \mathrm{m}$ and $40 \mu \mathrm{m}$ in Figure 3 .

As shown in Figure 3, we confirm that the plastic incremental strain that occurs in the neighborhood of the die corner radius is distributed on the die corner radius and the die side in the case of $R_{\mathrm{d}}=20 \mu \mathrm{m}$. However, the plastic incremental strain is distributed on the die corner radius only in case of $R_{\mathrm{d}}=40 \mu \mathrm{m}$. Next, we confirm the plastic incremental strain distribution for a stroke of 1.2 $\mathrm{mm}$. In this case, a gap between the die

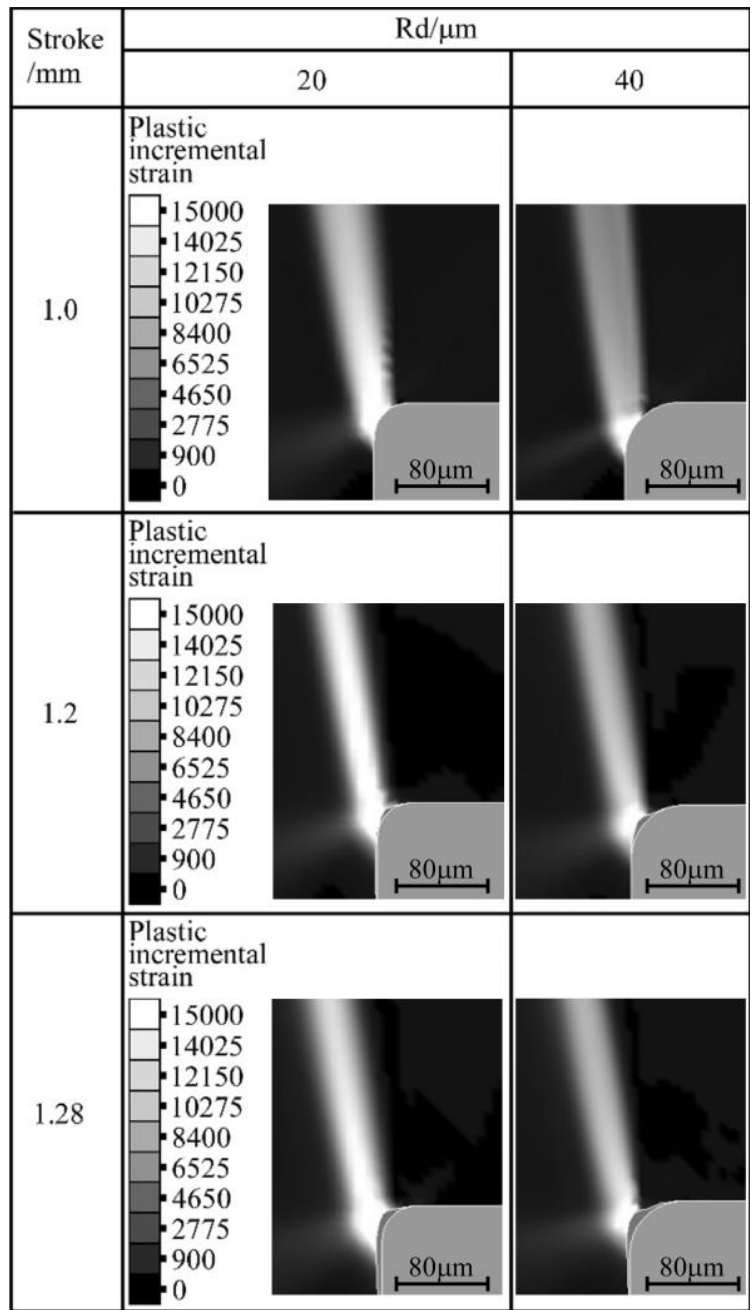

Figure 3. Plastic incremental strain distribution on neighborhood of die edge with every stroke.

and the blank occurs at the die corner radius in the cases of $R_{\mathrm{d}}=20 \mu \mathrm{m}$ and $40 \mu \mathrm{m}$. The gap is bigger in the case of $R_{\mathrm{d}}=40 \mu \mathrm{m}$ than in case of $R_{\mathrm{d}}=20 \mu \mathrm{m}$. For a stroke of $1.28 \mathrm{~mm}$, we can confirm that the gap is distributed on the die corner radius and the die side in the case of $R_{\mathrm{d}}=$ $20 \mu \mathrm{m}$. However, for the case in which $R_{\mathrm{d}}=40 \mu \mathrm{m}$, the gap is larger than that in the case of a stroke of $1.2 \mathrm{~mm}$. We cannot confirm the existence of a gap on the die side. Next, the plastic incremental strain distributions for a stroke of $1.2 \mathrm{~mm}$ in the cases of $R_{\mathrm{d}}=10 \mu \mathrm{m}, 20 \mu \mathrm{m}, 30$ $\mu \mathrm{m}$, and $40 \mu \mathrm{m}$ are shown in Figure 4.

As shown in Figures 4(a) and 4(b), in the cases of $R_{\mathrm{d}}$ $=10 \mu \mathrm{m}$ and $20 \mu \mathrm{m}$, the gap is distributed on the die corner radius and the die side. In case of $R_{\mathrm{d}}=10 \mu \mathrm{m}$, the gap is focused on the die side. However, in the case of $R_{\mathrm{d}}$ $=20 \mu \mathrm{m}$, the gap is focused on the die corner radius. As shown in Figures 4(c) and 4(d), in the cases of $R_{\mathrm{d}}=30$ $\mu \mathrm{m}$ and $40 \mu \mathrm{m}$, the gap is distributed on only on the die corner radius. We cannot confirm the existence of a gap 
on the die side. Therefore, when the die corner radius $R_{\mathrm{d}}$ increases, the domain that the gap is focused moves from the die corner radius to the die side. The gap is thought to satisfy the fracture condition, because the contact pressure is not focused in the gap. As shown in Figure 3, fracture is thought to occur from the end part of the gap for all die conditions, because, for a stroke of $1.28 \mathrm{~mm}$, high plastic incremental strain occurs at the end of the gap.

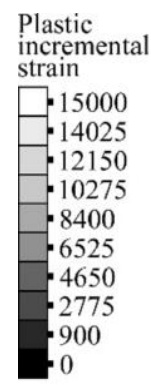

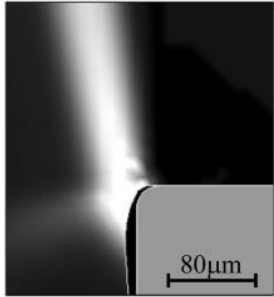

(a) $\mathrm{Rd}=10 \mu \mathrm{m}$

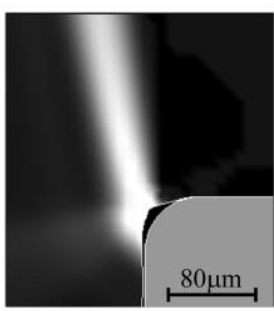

(c) $\mathrm{Rd}=30 \mu \mathrm{m}$

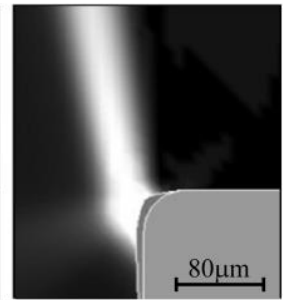

(b) $\mathrm{Rd}=20 \mu \mathrm{m}$

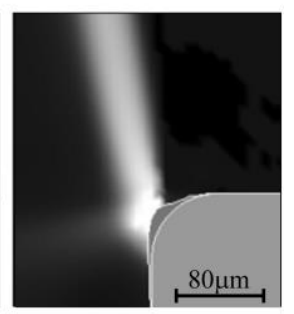

(d) $\mathrm{Rd}=40 \mu \mathrm{m}$
Figure 4. Plastic incremental strain distribution with a stroke of $1.28 \mathrm{~mm}$ on ever die abrasion status.

\subsection{Hydrostatic pressure}

Hydrostatic

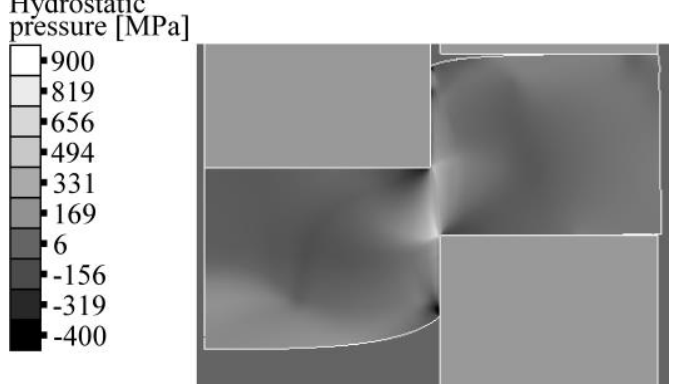

Figure 5. Hydrostatic pressure distribution with a stroke of $1 \mathrm{~mm}$ in case of $R_{\mathrm{d}}=20 \mu \mathrm{m}$
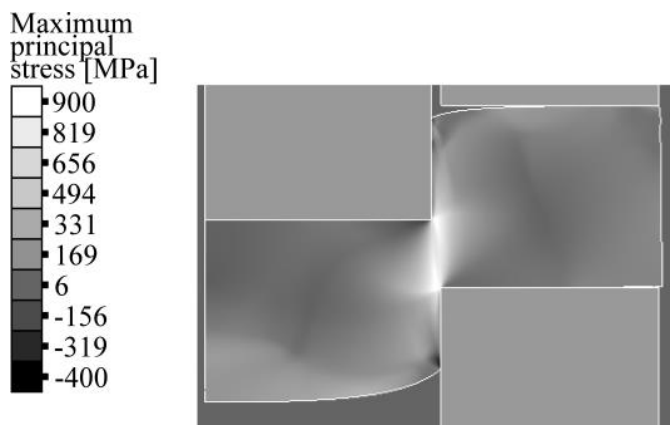

Figure 6. Maximum principal stress distribution with a stroke of $1 \mathrm{~mm}$ in case of $R_{\mathrm{d}}=20 \mu \mathrm{m}$
The hydrostatic pressure distribution, the maximum principal stress distribution, and the minimum principal stress distribution with a stroke of $1 \mathrm{~mm}$ in the case of $R_{\mathrm{d}}$ $=20 \mu \mathrm{m}$ are shown in Figure 5, Figure 6 and Figure 7.
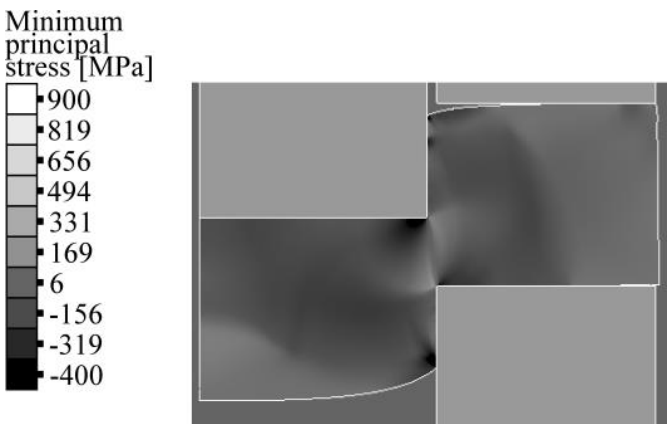

Figure 7. Minimum principal stress distribution with a stroke of $1 \mathrm{~mm}$ in case of $R_{\mathrm{d}}=20 \mu \mathrm{m}$

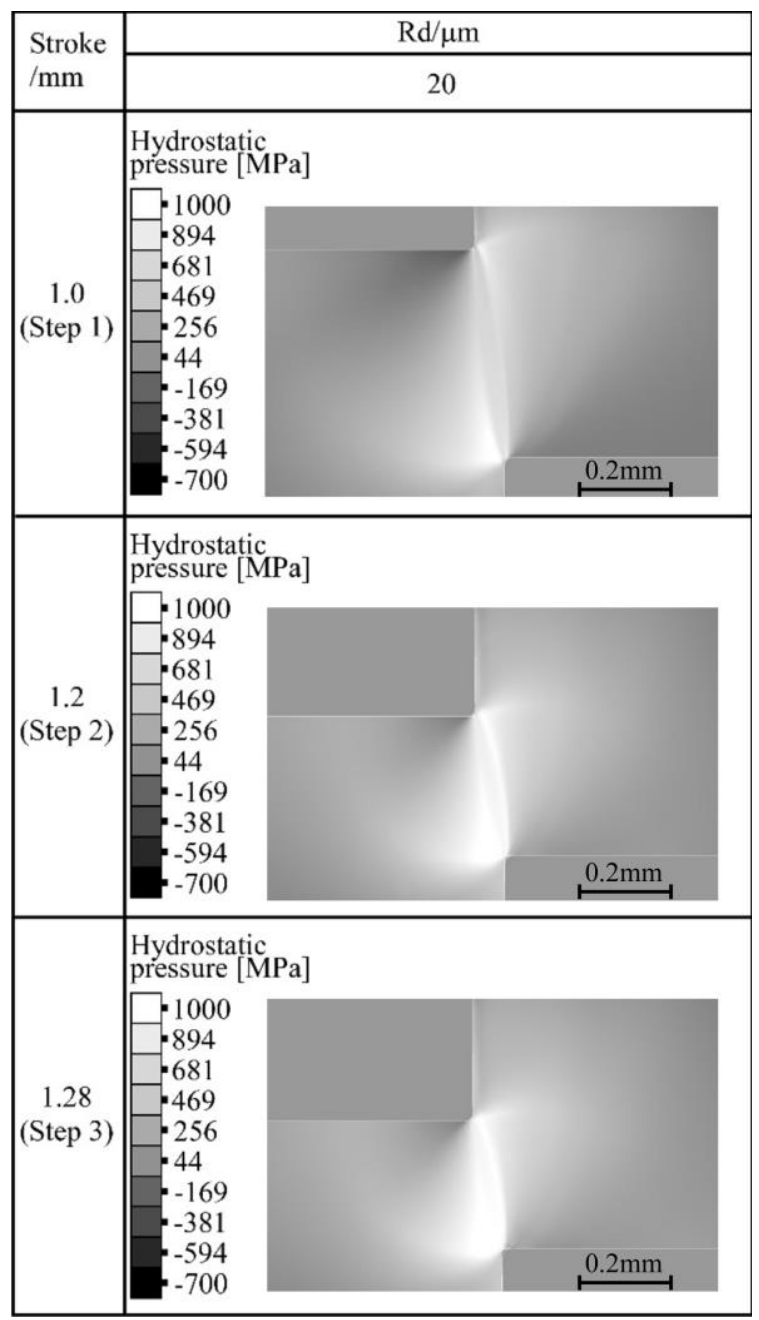

Figure 8. Hydrostatic pressure distribution with every stroke in case of $R_{\mathrm{d}}=20 \mu \mathrm{m}$

In the present study, the punching process exhibits a circumferential plane strain field because, as shown in Figure 5, Figure 6 and Figure 7, the mean of the maximum principal stress distribution and the minimum principal stress distribution is the same as the hydrostatic pressure distribution. Therefore, the mechanism of the punching process can be explained by the hydrostatic 
pressure. As shown in Figure 5, tensile stress occurs in the neighborhood of the die corner radius and the punch corner radius. The tensile stress in the neighborhood of the die edge is shown as a tensile stress field in Figure 6 and Figure 7. Compression stress occurred at the in bottom face of the punch, at the top face of the die, at the die corner radius is shown as a tensile stress field the punch side, and at the die side. Therefore, the blank on the die top face is expected to flow toward the punch side. As for the blank on punch top face is toward die side. Next, the hydrostatic pressure distributions for strokes of $1 \mathrm{~mm}, 1.2 \mathrm{~mm}$, and $1.28 \mathrm{~mm}$ in the case of $R_{\mathrm{d}}$ $=20 \mu \mathrm{m}$ are shown in Figure 8 .

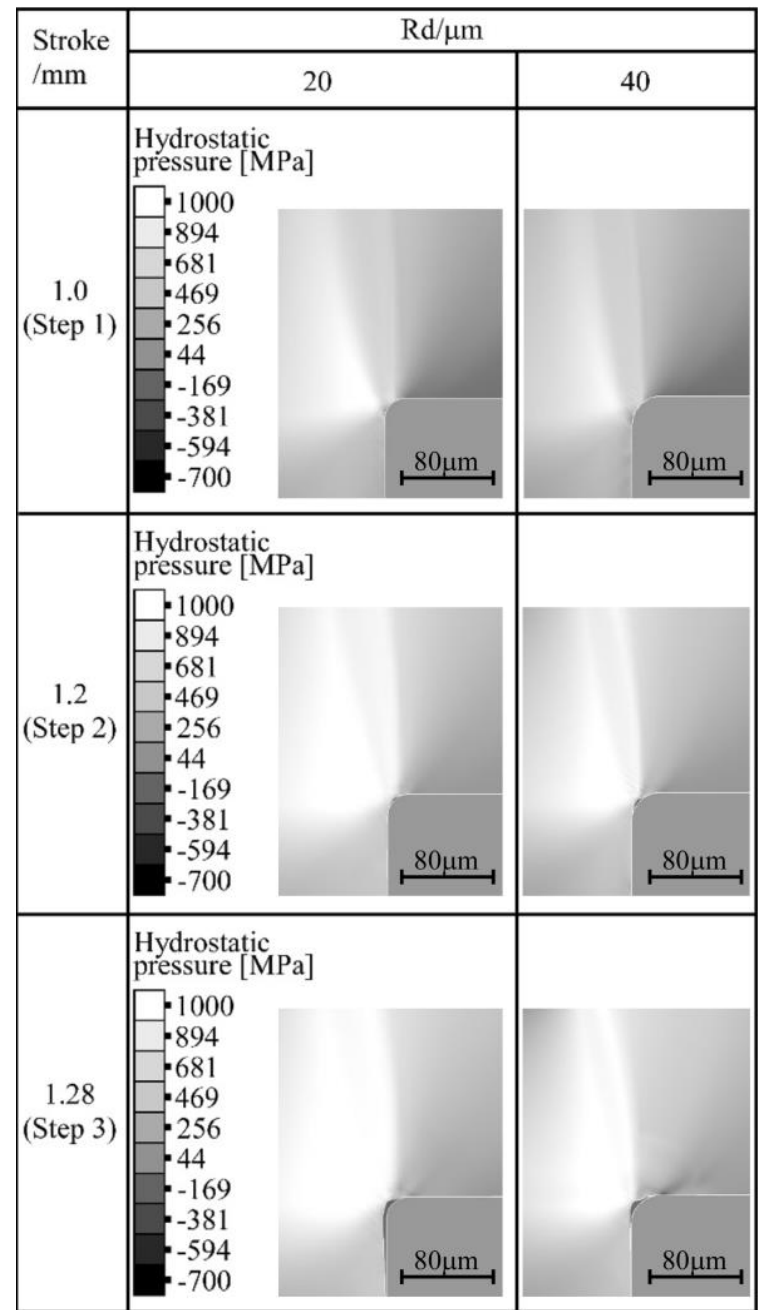

Figure 9. Hydrostatic pressure distribution on neighborhood of die edge.

As shown in Figure 8, we confirmed that the stress distribution for the punching process is divided into three steps. In Step 1, the hydrostatic pressure in the domain linking the punch corner radius and the die corner radius is approximately $0 \mathrm{MPa}$. This domain is thought to be a pure shear domain. Next, the hydrostatic pressure distributions in the neighborhood of the die corner radius for strokes of $1 \mathrm{~mm}, 1.2 \mathrm{~mm}$, and $1.28 \mathrm{~mm}$ in the case of $R_{\mathrm{d}}=20 \mu \mathrm{m}$ and $40 \mu \mathrm{m}$ are shown in Figure 9.

The tensile stress in the neighborhood of the domain is shown. The tensile stress in the neighborhood of the die corner radius and the punch corner radius is higher

than elsewhere. In Step 2, the tensile stress appears in the pure shear domain in Step 1. In Step 3, the tensile stress in this domain is approximately the same as that in the neighborhood of the die corner radius. Next, the hydrostatic pressure distributions in the neighborhood of the die corner radius for $R_{\mathrm{d}}=20 \mu \mathrm{m}$ and $40 \mu \mathrm{m}$ are shown in Figure 9. As shown in Figure 9, in Step 1, the tensile stress is distributed only on the end part of the die corner radius. Compression stress occurs at locations other than the die corner radius. The tensile stress in Step 2 is higher than that in Step 1. Moreover, a gap appears between the die corner radius and the blank. The high tensile stress domain in Step 3 is larger than that in Step 2. The tensile stress domain for $R_{\mathrm{d}}=40 \mu \mathrm{m}$ is larger than that for $R_{\mathrm{d}}=20 \mu \mathrm{m}$. Therefore, it's expected that gap form varies depending on the level of die corner radius.

\subsection{Equivalent plastic strain}

The equivalent plastic strain distributions for a stroke of 1 $\mathrm{mm}$ in the cases of $R_{\mathrm{d}}=10 \mu \mathrm{m}, 20 \mu \mathrm{m}, 30 \mu \mathrm{m}$, and 40 $\mu \mathrm{m}$ are shown in Figure 10. As shown in Figure 10, high equivalent plastic strain is distributed over the range of the die side from the die corner radius. Therefore, the blank over the range from the die corner radius to the die side is thought to be brittle. We confirmed that die wear has little effect on equivalent plastic strain.

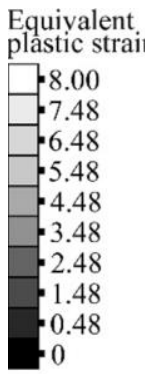

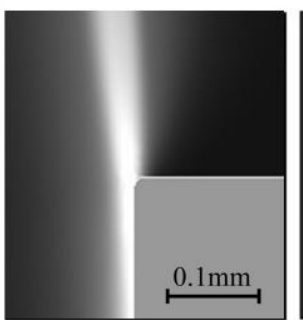

(a) $\mathrm{Rd}=10 \mu \mathrm{m}$

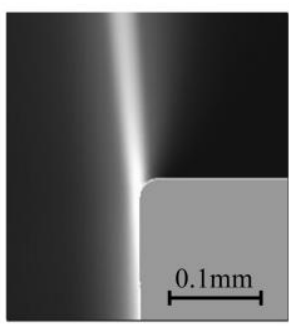

(c) $\mathrm{Rd}=30 \mu \mathrm{m}$
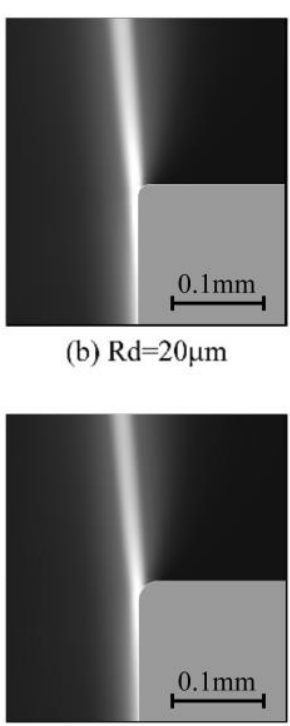

(d) $\mathrm{Rd}=40 \mu \mathrm{m}$ (b) $\mathrm{Rd}=20 \mu \mathrm{m}$

Figure 10. Equivalent plastic strain distribution with a stroke of $1 \mathrm{~mm}$.

\section{Discussion}

The plastic incremental strain, hydrostatic pressure, and equivalent plastic strain are high for a stroke of $1 \mathrm{~mm}$, as shown in Figure 11. As shown in Figure 11, the high plastic incremental strain occurred at the die corner radius. And, the high equivalent plastic strain is distributed over the range of the die side from the die corner radius. However, high hydrostatic pressure 
occurred at the neighborhood of the die corner radius. The domain that high equivalent plastic strain was shown is thought to be brittle. The plastic incremental strain shows the deformation volume. Therefore, the location at which the equivalent plastic strain overlaps the plastic incremental strain is likely to exhibit crack formation. Cracks are thought to progresses as a result of the hydrostatic pressure of the tensile field. Therefore, in case of $\mathrm{Rd}=20 \mu \mathrm{m}$, crack is thought to occurred over the range of the die side from the die corner radius. In case of $\mathrm{Rd}=40 \mu \mathrm{m}$, crack is thought to occurred on die corner radius. The origin of crack formation differs according to the level of die wear.

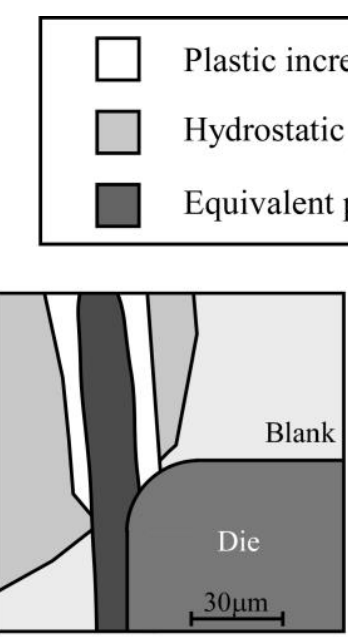

(a) $\mathrm{Rd}=20 \mu \mathrm{m}$

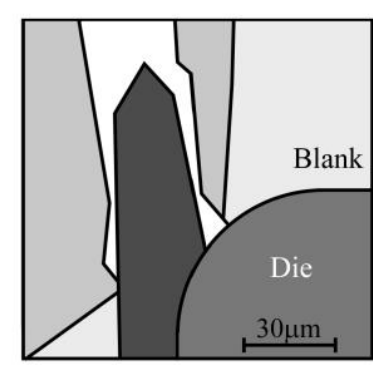

(b) $\mathrm{Rd}=40 \mu \mathrm{m}$
Figure 11. High value of plastic incremental strain, hydrostatic pressure and equivalent plastic strain with a stroke of $1 \mathrm{~mm}$.

\section{Conclusion}

We analyze the punching process while considering die wear. We varied the die wear amount as $10 \mu \mathrm{m}, 20$ $\mu \mathrm{m}, 30 \mu \mathrm{m}$, and $40 \mu \mathrm{m}$. We investigated the hydrostatic pressure distribution, the equivalent plastic strain distribution, and the plastic incremental strain distribution for different levels of die wear in the neighborhood of the die corner radius. The results obtained are summarized as follows.
(1) In the plastic incremental strain distribution, the thin layer shear is thought to occur in the domain linking the punch corner radius and the die corner radius.

(2) The gap between the die and the blank occurs at the die corner radius for a stroke of $1.2 \mathrm{~mm}$. Moreover, the gap differs depending of the level of die corner radius.

(3) In this punching process, the stress distribution of the thin layer shear is divided into three steps.

(4) We confirmed that the level of die wear has little effect on the equivalent plastic strain.

(5) The origin of crack formation differs according to the level of die wear.

\section{References}

1. K. Junlapen, M. Kubo, K. Mizuochi, N. Koga, P. Keawtatip, ICTP, 158-163, (2008)

2. S. Thipprakmas, M. Jin, M. Murakawa, ICTP, Oct. 28-31, 889-894, (2002)

3. T. Maeda, I. Aoki, J. Fac. Eng. Univ. Tokyo (B), 343,537-577 (1978)

4. N. Hatanaka, K. Yamaguchi, N. Takakura, T. Iizuka, J. Mat. Pro. Tec., 140, 628-634(2003)

5. H. Jaafar, K. Mori, Y. Abe, K. Nakanishi, Journal of Materials Processing Technology, 227, 190-199, (2016)

6. T. Iizuka, N. Hatanaka, T. Ishihara, N. Takakura, ICTP, 4-1, 2330-2335, (2008)

7. T. Iizuka, Wei. Yu, N. Hatanaka, N. Takakura, J. Jpn. Soc. Technol., (2nd report), 337, (2009)

8. D. Sakamoto, T. Iizuka, N. Hatanaka, N. Takakura, Metal Forming, 537, (2012)

9. S. H. Jeong, J. J. Kang, S. I. Oh, J. ICTP, 631-634, (1996)

10. N. Hatanaka, K. Yamaguchi, N. Takakura, Journal of Materials Technology, 139, 64-70, (2003)

11. Y. Yoshida, S. Sumikawa, N. Yukawa, T. Ishikawa, Ad. Tec. Pla., 2 883-888, (2002)

12. A. Ahmed, H. Muhamad, IIUM, Vol. 13, 153-159, (2012) 